\title{
Pemanfaatan Minyak Goreng Bekas Menjadi Sabun Mandi
}

\author{
Antonius Prihanto* dan Bambang Irawan \\ Program Studi Teknik Kimia, Politeknik Katolik Mangunwijaya \\ JI. Sriwijaya 104 Semarang 50241 Indonesia \\ Email : antoniusprihanto@ymail.com
}

\begin{abstract}
Abstrak
Rekayasa produk limbah untuk mengurangi pencemaran dapat memberikan nilai lebih terhadap produk yang di hasilkan. Upaya pemanfaatan limbah minyak goreng bekas untuk diolah menggunakan rekayasa proses menjadi produk yang lebih berguna berupa sabun mandi. Penelitian ini dilakukan untuk mengkaji pengaruh konsentrasi $\mathrm{NaOH}$ dan suhu proses terhadap kualitas produk sabun mandi. Pada tahap persiapan, minyak goreng bekas dibersihkan dari pengotornya melalui proses filtrasi dan penetralan dengan larutan $\mathrm{NaOH}$. Minyak goreng bekas yang telah murni dan jernih selanjutnya direaksikan dengan larutan $\mathrm{NaOH}$ dengan variasi konsentrasi $\mathrm{NaOH} 25 \%, 30 \%, 35 \%, 40 \%$ dan $45 \%$ pada suhu proses dengan variasi $30{ }^{\circ} \mathrm{C}, 35^{\circ} \mathrm{C}, 40$ ${ }^{\circ} \mathrm{C}, 45{ }^{\circ} \mathrm{C}$ dan $50{ }^{\circ} \mathrm{C}$. Hasil penelitian menunjukkan pada konsentrasi larutan $\mathrm{NaOH} 25 \%$ menghasilkan kualitas sabun terbaik dengan kadar alkali paling kecil yaitu $0.0272 \%$
\end{abstract}

Kata kunci : minyak goreng bekas; sabun mandi; rekayasa

\section{PENDAHULUAN}

Penggunaan minyak goreng yang berulang-ulang akan menimbulkan kerusakan, karena adanya proses hidrolisis, oksidasi. Kerusakan minyak goreng dapat dilihat dari aroma minyak yang menjadi kurang enak (tengik), serta warna minyak goreng yang berubah menjadi gelap. Minyak goreng bekas dapat mengakibatkan keracunan dalam tubuh dan dapat mengakibatkan berbagai macam penyakit. Minyak goreng bekas dapat mengendapkan lemak dalam pembuluh darah, dan kanker hati (Guenther, 1987). Minyak goreng bekas adalah minyak goreng yang telah rusak sehingga tidak layak untuk dikonsumsi. Minyak goreng bekas ini dapat kita katagorikan sebagai limbah dari proses penggorengan.

Saat ini sudah banyak penelitian yang mengolah minyak goreng bekas ini menjadi produk yang nilai ekonominya meningkat dibanding minyak goreng bekas. Banyak penelitian yang telah berhasil mengolah minyak goreng bekas menjadi biodiesel (Setiawati, 2012). Walaupun banyak penelitian yang berhasil membuat biodiesel dari minyak goreng bekas, ternyata pemasaran biodiesel banyak mengalami kendala. Tidak adanya subsidi dari pemerintah, sehingga harga biodiesel lebih mahal dibanding solar. Saat ini belum ada sistem pemasaran biodiesel yang terstruktur dari Pertamina. Masih kurangnya sosialisasi dari pemerintah tentang biodiesel sehingga dikalangan masyarakat muncul stigma bahwa solar merupakan bahan bakar yang lebih baik untuk mesin disel dibanding biodiesel merupakan kendala dalam pemasaran biodiesel (Sunita 2011).

Minyak goreng bekas dapat diolah menjadi sabun mandi baik dalam bentuk padat maupun cair (Wijana dkk., 2010;.Priani, 2010). Pemanfaatan sabun Sabun dihasilkan dari proses hidrolisis minyak atau lemak menjadi asam lemak bebas dan gliserol yang dilanjutkan dengan proses saponifikasi menggunakan basa $(\mathrm{KOH}$ atau $\mathrm{NaOH}$ ). Asam lemak bebas yang berikatan dengan basa ini dinamakan sabun (Ketaren, 1986). Reaksi penyabunan merupakan reaksi yang pada awalnya berjalan lambat karena minyak dan larutan alkali merupakan larutan yang tidak saling larut (Immiscible). Tetapi setelah terbentuk sabun maka 
kecepatan reaksi akan meningkat, karena produk yang terbentuk berperan sebagai katalisator reaksi berikutnya.

Minyak goreng bekas ini bila langsung digunakan sebagai bahan baku pembuatan sabun mandi hasilnya kurang baik.. Sabun mandi dari minyak goreng bekas ini mungkin dari sisi warna tidak menarik karena kotor dan gelap dan dari sisi aroma mungkin aroma dari bahan yang digoreng masih akan melekat pada prodik sabun. Untuk mengnghasilkan produk sabun yang secara fisik menarik dan dari sisi aroma harum, maka minyak goreng bekas ini harus dimurnikan dulu. Proses pengolahan minyak goreng bekas yang paling sering dilakukan adalah dengan metode adsorbsi. Beberapa peneliti telah melakukan penelitian pemurnian minyak goreng dengan metode adsorbsi. Kusumastuti (2004) dan Widayat dkk. (2005) memurnikan minyak goreng bekas menggunakan adsorben zeolit asam. Nurul (2008) memurnikan miyak goreng bekas menggunakan kulit pisang kepok dan Nasir dkk. (2014) menggunakan karbon aktif. Kelebihan karbon aktif sebagai adsorben untuk pemurnian minyak goreng bekas sebagai bahan penyerap warna. Karbon aktif juga dapat mengurangi jumlah kadar asam lemak bebas yang dihasilkan oleh minyak goreng yang sudah digunakan untuk menggoreng (Ketaren, 1986). Pemanfaatan minyak goreng bekas menjadi sabun mandi akan meningkatkan nilai ekonomis dari minyak goreng bekas.

\section{METODOLOGI}

Alat yang digunakan penelitian ini meliputi neraca analitis, hotplate dengan magnetik stirrer, gelas piala, erlenmeyer, gelas ukur, labu takar, buret, pipet volume dan pipet tetes. Proses penelitian terbagi dalam dua tahap yaitu tahap perlakuan pendahuluan bahan baku yang meliputi filtrasi dan adsorbsi dan tahap pembuatan produk. Filtrasi :Proses ini bertujuan untuk memisahkan minyak dari pengotor berupa materi padat. Caranya minyak goreng bekas disaring dengan menggunakan kertas saring. Hasil filtrasi berupa minyak ang telah bebas dari pengotor berupa zat padat. Adsorbsi : Proses ini bertutujuan untuk menghilangkan warna gelap minyak, bau minyak. Hasil dari proses adsorbs ini adalah minyak yang jernih dan tak berbau.
Caranya minyak dipanaskan pada suhu $60{ }^{\circ} \mathrm{C}$ ditambah $2 \%$ karbon aktif dan diaduk selama 30 menit. Selanjutnya minyak disaring untuk memisahkan minyak dari karbon aktif dan pengotor yang telah teradsorbsi. Tahap pembuatan produk :200 ml minyak goreng bekas yang telah dimurnikan dipanaskan sesuai suhu proses yang diinginkan $\left(30{ }^{\circ} \mathrm{C}, 35^{\circ} \mathrm{C}, 40{ }^{\circ} \mathrm{C}, 45^{\circ} \mathrm{C}\right.$ dan $50{ }^{\circ} \mathrm{C}$ ) di tambah $60 \mathrm{ml}$ larutan $\mathrm{NaOH}$ dengan konsentrasi bervariasi $(25 \%, 30 \%, 35 \%, 40 \%$ dan $45 \%)$ dengan pengadukan sampai trace. Setelah mencapai keadaan trce, campuran ditambah pewarna makanan dan parfum secukupnya dan diaduk perlahan agar homogen dan dituang ke cetakan sabun. Sabun didiamkan selama 2 minggu agar proses penyabunan berjalan sempurna. Setelah 2 minggu sabun siap untuk diuji kadar air dan kadar alkali bebasnya.

\section{HASIL DAN PEMBAHASAN}

\section{Pengaruh konsentrasi $\mathrm{NaOH}$ terhadap kadar alkali bebas.}

Secara teori peningkatan jumlah $\mathrm{NaOH}$ akan meningkatkan alkali bebas dari sabun yang terbentuk pada proses pembuatan sabun, terutama setelah titik kesetaraannya telah terlewati. Setelah titik kesetaraan terlewati, peningkatan konsentrasi $\mathrm{NaOH}$ akan meningkatkan alkali bebas sabun. Pengaruh konsentrasi $\mathrm{NaOH}$ terhadap alkali bebas dari sabun telah diuji pada suhu $40{ }^{\circ} \mathrm{C}$.seperti yang ditunjukkan Gambar 1.

Peningkatan konsentrasi $\mathrm{NaOH}$ pada proses pembuatan sabun mandi akan meningkatkan alkali bebas dari sabun. Hal ini terjadi karena semakin besar konsentrasi $\mathrm{NaOH}$ yang ditambahkan berarti semakin banyak $\mathrm{NaOH}$ yang ditambahkan sehingga semakin banyak $\mathrm{NaOH}$ yang tersisa dari reaksi penyabunan. Sisa $\mathrm{NaOH}$ dari reaksi penyabunan ini terdapat dalam sabun sebagai alkali bebas. Pembuatan sabun dari $100 \mathrm{cc}$ minyak dengan menambahkan $30 \mathrm{cc}$ larutan $\mathrm{NaOH} 25 \%$ hingga larutan $\mathrm{NaOH} 40 \%$ telah memenuhi syarat standar mutu sabun mandi menurut SNI 06-3532-1994 yaitu alkali bebas maksimum $0,1 \%$ sebagai $\mathrm{NaOH}$. Pembuatan sabun dengan larutan $\mathrm{NaOH} 25 \%$ menghasilkan sabunkecil yaitu 0,0272 \%. Sabun dengan kadar alkali bebas semakin kecil akan semakin baik 
untuk kulit karena tidak menyebabkan iritasi pada kulit.

\section{Pengaruh konsentrasi $\mathrm{NaOH}$ terhadap kadar air} Secara stokiometri peningkatan konsentrasi larutan $\mathrm{NaOH}$ untuk volume yang sama pada proses pembuatan sabun akan semakin menurunkan kadar air dari sabun. Pengaruh peningkatan kadar larutan $\mathrm{NaOH}$ terhadap kadar air pada proses pembuatan sabun telah diuji pada suhu $40{ }^{\circ} \mathrm{C}$ seperti yang ditunjukkan Gambar 2.

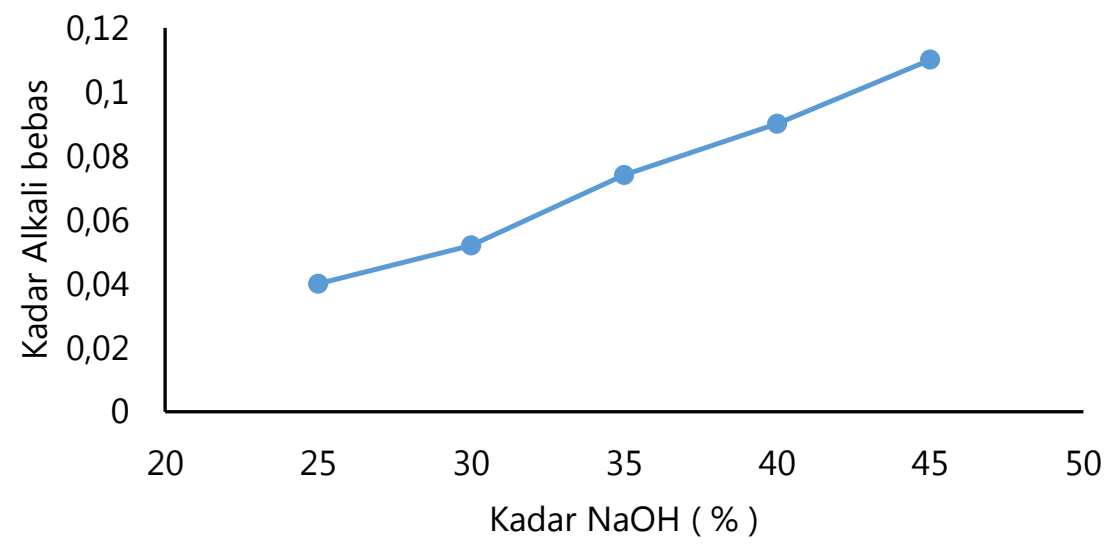

Gambar 1. Pengaruh Konsentrasi $\mathrm{NaOH}$ Terhadap Kadar Alkali Bebas

Tabel 1. Syarat Mutu Sabun Mandi ( SNI 06-3532-1994)

\begin{tabular}{clccc}
\hline No & \multicolumn{1}{c}{ Uraian } & Tipe 1 & Tipe 2 & Tipe 3 \\
\hline 1 & Kadar air, \% & $<15 \%$ & $<15 \%$ & $<15 \%$ \\
2 & Jumlah asam lemak, \% & $>70$ & $64-70$ & $>70$ \\
3 & Alkali bebas & Maks 0,1 & Maks 0,1 & Maks 0,1 \\
& Dihitung sebagai $\mathrm{NaOH}, \%$ & Maks 0,14 & Maks 0,14 & Maks 0,14 \\
& Dihitung sbagai $\mathrm{KOH} \%$ & $<2,5$ & $<2,5$ & $<2,5$ \\
4 & Asam lemak bebas, \% & negatif & negatif & negatif \\
5 & Minyak mineral & & & \\
\hline
\end{tabular}

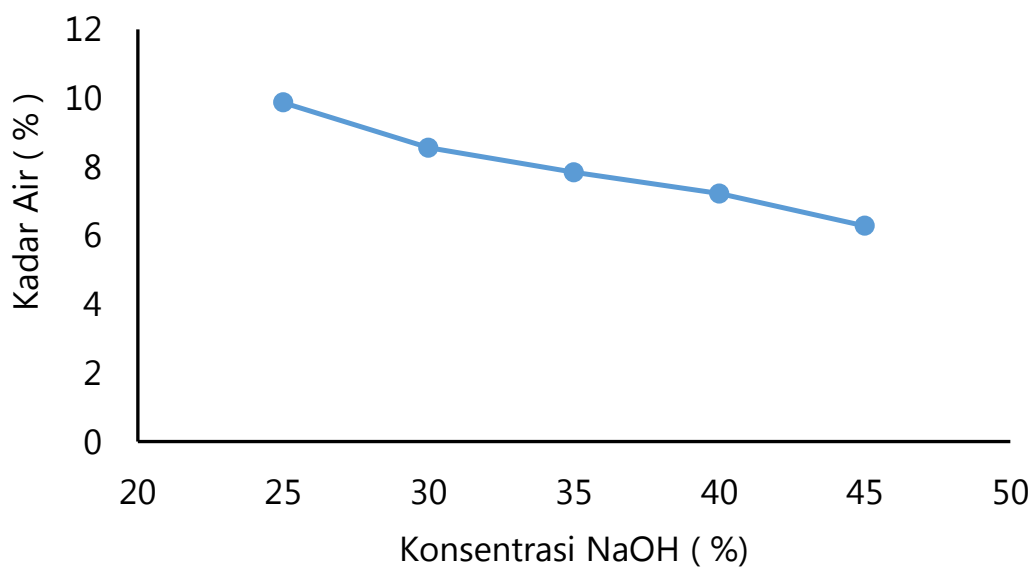

Gambar 2. Pengaruh Konsentrasi $\mathrm{NaOH}$ terhadap Kadar Air. 
Gambar 2. Menunjukkan bahwa peningkatan konsentrasi $\mathrm{NaOH}$ pada proses pembuatan sabun mandi akan menurunkan kadar air dari sabun. Hal ini terjadi karena semakin besar konsentrasi $\mathrm{NaOH}$ yang ditambahkan untuk volume larutan yang sama berarti semakin banyak $\mathrm{NaOH}$ yang mengisi larutan tersebut sehingga jumlah air yang ada akan semakin menurun. Pembuatan sabun dari 100 cc minyak dengan menambahkan 30 cc larutan $\mathrm{NaOH} 25 \%$ hingga larutan $\mathrm{NaOH} 45 \%$ telah memenuhi syarat standar mutu sabun mandi menurut SNI yaitu kadar air kurang dari $15 \%$.

\section{Pengaruh suhu proses terhadap alkalinitas}

Secara teori peningkatan suhu proses tidak akan mengubah reaktan yang terkonversi menjadi sabun. Adanya kandungan alkali bebas dalam sabun menunjukkan bahwa $\mathrm{NaOH}$ tidak tidak dapat terkonversi lagi jadi sabun karena minyak telah habis tersabunkan. Pengaruh konsentrasi suhu proses terhadap alkali bebas dari sabun telah diuji pada kadar $\mathrm{NaOH} 25 \%, 30 \%$ dan35\% seperti yang ditunjukkan Gambar 3. Meningkatnya konsentrasi $\mathrm{NaOH}$ pada proses pembentukan sabun tidak menunjukkan tren kenaikan atau penurunan kadar alkali bebas dari sabun. Menaikkan suhu proses memang akan mempercepat reaksi atau mempercepat tercapainya trace pada pembuatan sabun, tetapi tidak akan menambah jumlah sabun yang terbentuk atau menurunkan kadar alkali bebas dalam sabun.

\section{Pengaruh suhu terhadap kadar air dari sabun.}

Secara stokiometri kadar air dari sabun sangat ditentukan dari air yang telah terbawa dari

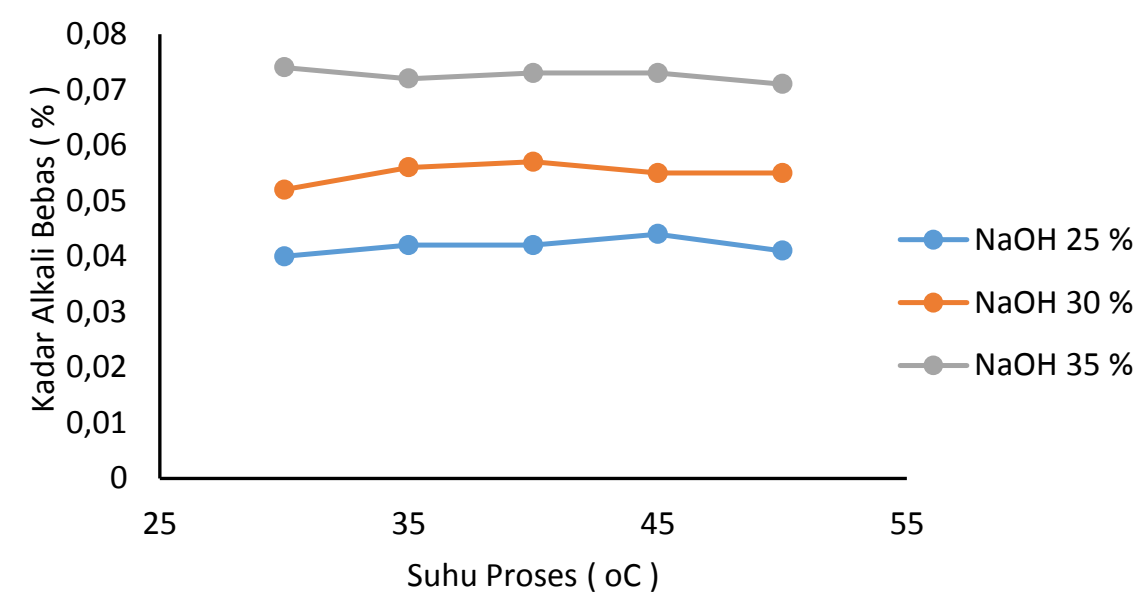

Gambar 3. Pengaruh Suhu Proses terhadap Kadar Alkali Bebas

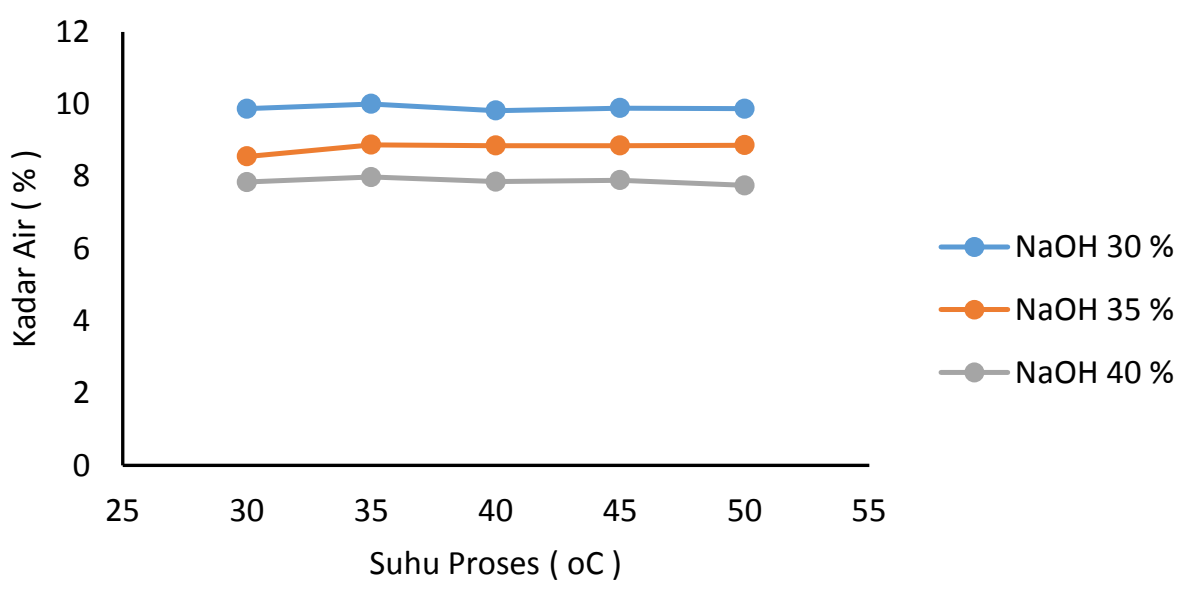

Gambar 4. Pengaruh Suhu Proses terhadap Kadar Air 
larutan $\mathrm{NaOH}$ yang ditambahkan pada minyak. Kadar air sabun dipengaruhi oleh konsentrasi larutan $\mathrm{NaOH}$ yang ditambahkan, tetapi suhu proses tidak ditentukan oleh suhu proses. Pengaruh suhu proses terhadap kadar air sabun yang terbentuk telah diuji pada berbagai konsentrasi $\mathrm{NaOH}$ seperti yang ditunjukkan pada Gambar 4. Menunjukkan bahwa perbedaan kadar air terjadi karena perbedaan konsentrasi $\mathrm{NaOH}$ yang ditambahkan ke dalam minyak. Peningkatan suhu proses tidak menunjukkan tren kenaikan atau penurunan kadar air pada proses pembuatan sabun.

\section{KESIMPULAN}

Pembuatan sabun dengan konsentrasi $\mathrm{NaOH} 25 \%$ hingga $40 \%$ untuk berbagai suhu proses telah memenuhi syarat mutu sabun menurut SNI. Pembuatan sabun dari minyak goreng bekas dengan konsentrasi $\mathrm{NaOH} 25 \%$ menghasilkan sabun terbaik dengan kandungan alkalinitas terendah yaitu $0,0272 \%$.

\section{DAFTAR PUSTAKA}

Anonymous, 1994. SNI 06-3532-1994 Standar Mutu Sabun Mandi. Jakarta: Dewan Standarisasi Nasional

Guenther, E. 1987. Minyak Atsiri. Diterjemahkan oleh R.S. Ketaren dan R. Mulyono. Jakarta, UI

Ketaren, S. 1986. Pengantar Teknologi Minyak dan Lemak Pangan. Cetakan Pertama. Jakarta : UIPress.

Kusumastuti. 2004. Kinerja Zeolit Dalam Memperbaiki Mutu Minyak Goreng Bekas. J.
Teknol. Industri Pangan Universitas Negeri Semarang. XV(2)

Nasir, N.W., Nurhaeni \& Musafira. 2014. Pemanfaatan Arang Aktif Kulit Pisang Kepok (musa normalis) sebagai Adsorben untuk Menurunkan Angka Peroksida dan Asam Lemak Bebas Minyak Goreng Bekas. J. Natural Sci. 3:18-30

Nurul, F.S. \& Widiastuti, N. 2008. Adsorpsi Cu) pada Zeolit yang Disintesis dari Abu Dasar Batubara PT Ipmomi Paiton. J. Zeolit Ind. 7(1):1-11

Priani, S.E. \& Lukmayani, Y., 2010. Pembuatan Sabun Transparan Berbahan Dasar Minyak Jelantah serta Hasil Uji Iritasinya pada Kelinci. Prosiding SnaPP, Edisi Eksakta. ISSN: 20893582.

Setiawati, E. \& Edwar, F. 2012. Teknologi Pengolahan Biodiesel dari Minyak Goreng Bekas dengan Teknik Mikrofiltrasi dan Transesterifikasi sebagai Alternatif Bahan Bakar Mesin Diesel. J. Riset Industri. 6(2): 117127.

Sunyta. 2011. Proses Pembuatan Biodisel dan Kendala Pemasaran Biodisel di Indonesia. Kompasiana 21 desember 2011

Widayat. 2006. Optimasi Proses Adsorbsi Minyak Goreng Bekas dengan Adsorbent Zeolit Alam : Studi Pengurangan Bilangan Asam. Jurusan Teknik Kimia, Fakultas Teknik, Universitas Diponegoro. Semarang. J. Teknik Gelagar. 17(1):77-82

Wijana, S., Pranowo, D. \& Taslimah, M.Y. 2010. Penggandaan Skala Produksi Sabun Cair dari Daur Ulang Minyak Goreng Bekas. J. TeknoL. Pertanian. 11(2):114-122 